\title{
Effect of application of ice pack on reducing pain during the arterial puncture
}

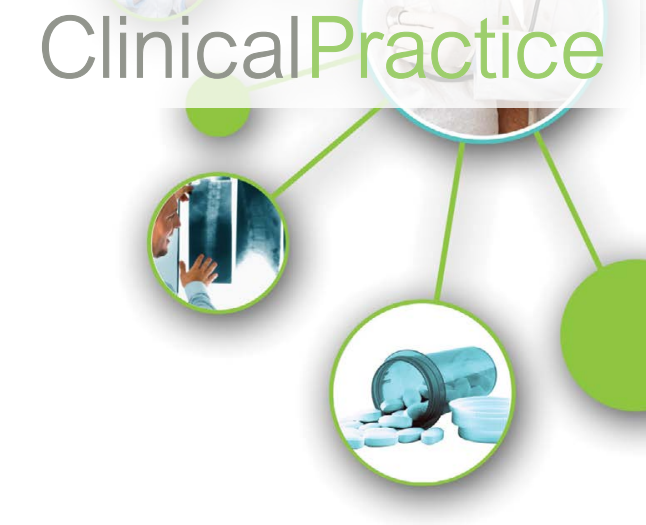

Background: Arterial puncture procedure is frequently performed by critical care nurses without pain management. The pain associated with arterial puncture can cause anxiety and discomfort, the evidence regarding efficiency of nonpharmacologic pain management techniques including cold application is limited and needs further researches.

Objective: To investigate the effect of the local application of ice pack before procedure on reducing pain experienced by patients during the arterial puncture

Materials and Methods: Quasi experimental study was undertaken among patients admitted to critical care units affiliated to Cairo University Hospital in Egypt. One hundred patients were randomly assigned to two groups. The study group $(n=50)$ received local application of ice pack before radial arterial puncture, whereas the control group $(n=50)$ received no intervention before radial arterial puncture. Pain immediately after the arterial puncture was scored on a visual analog scale (VAS) from 0 to 10 for both groups.

Results: The immediate mean pain score after the arterial puncture were $7.36 \pm 1.34$ and $7.88 \pm 0.79$ for the study and control group, respectively $(\mathrm{p}<0.05)$. There was significant statistical difference between them $(\mathrm{t}=2.36)$. The mean of heart rate during the procedure were $78 \pm 11.24 \mathrm{~b} / \mathrm{min}$ for the study group and $86 \pm 6.37 \mathrm{~b} / \mathrm{min}$ for the control group. There was significant statistical difference between them $(t=1.82, p<0.05)$

Conclusion: The research results showed that cold pack could be effective for relieving pain during arterial puncture. However, further researches are needed in different critical care settings and emergency units in different geographical areas to ensure generalizability of results.

\section{KEYWORDS: arterial puncture, pain, ice pack}

\section{Introduction}

Percutaneous puncture of radial artery can be painful for patients [1]. It is one the most common procedures used in patients with cardio-respiratory disease for analysis of blood gases [2]. Multiple punctures are required before a successful arterial blood gases (ABG) is withdrawn. Pain related to arterial puncture can cause anxiety, particularly in patients who needs frequent analysis of blood gases to assess their respiratory function [3]. This procedure is frequently performed by critical care nurses without pain management [4]. Accordingly, associated pain may cause some patients to avoid the nursing care $[5,6]$.

Previous researchers investigated different methods for reducing pain during arterial punctures. They listed strategies for pain management to include pharmacological interventions $[1,2,7,8]$. Use of local anesthesia to decrease pain associated with arterial puncture is one of the pharmacological methods that frequently mentioned in the previous studies [9]. Use of local anesthetic drug before arterial puncture has been efficient in relieving pain induced by withdrawal of arterial sample $[1,10]$. However, injection of anesthetics intradermally are underutilized and this is interpreted by the belief that injection of fluids into the layers of skin causes severe pain similar to pain produced by the arterial puncture and make the radial artery is difficult to palpate [1]. Moreover, clinicians are still confused to use such methods
Nahla Shaaban Khalil*

Faculty of Nursing, Cairo University, Giza, Egypt

*Author for correspondence:

nahlakhalil28@yahoo.com 
due to induced pain from administering anesthetics through intra-dermal route, onset of action and duration of administration and [5].

In addition researchers listed strategies for pain management to include non-pharmacological interventions such as heat and cold application $[7,8]$. Cold application has been used since old as an effective technique to relieve pain [11]. As well, relieving pain by cold pack application was formally utilized by ancient Egyptians, Persians, and Romans [12]. Pain relief by local cold pack applications has been widely used in various injuries $[13,14]$. The most common ice pack applications which have been discussed by many authors are relief of post-operative pain, and minimizing the discomfort of intradermal injection of anesthetic drugs [15] and this is explained formerly by researchers that application of local ice packs delay nerve conduction velocity and increase pain tolerance [16].

After reviewing the extensive related literature, it was found that few studies researched nonpharmacological interventions to relieve pain induced by arterial puncture. Therefore, the aim of this study was to assess the effect of the ice pack application on the pain level perceived by patients during puncture of radial artery.

\section{Purpose of the study}

To investigate the effect of the local application of ice pack on reducing pain perceived by patients during puncture of radial artery .

\section{Materials and methods}

\section{Design}

Quasi-experimental design was utilized among critically ill patients in medical critical care and emergency units affiliated to Kasr-Aini Hospital in Egypt.

\section{- Participants of the study:}

A convenient sample of 100 patients was recruited and divided randomly into the study and control groups. The eligibility criteria included fully conscious adult patients who able to describe their pain. Exclusion criteria included patients with difficult palpation of radial pulse, with more than one puncture trial to access the radial artery, AV fistula for hemodialysis, Raynaud's phenomenon, burn/ scar over the radial artery, positive Allen test. Also, patient who underwent muscle relaxant or sedative drugs more than one attempt, and for dialysis.

\section{Instrument}

\section{Base line data}

It included age, gender, diagnosis, and previous arterial puncture.

\section{- Pain visual analog scale (VAS)}

All patients in the study and control groups were asked to quantify their pain level utilizing visual analog scale(VAS) that ranged from (0 to 10) immediately after withdrawing the arterial sample. VAS is sufficiently reliable to be used to assess acute pain in emergency settings. The reliability co-efficient for VAS was 0.9 in 2002 [17].

\section{Recording pulse rate}

Heart rate was obtained utilizing Pulseoximeter before and during the withdrawal of arterial sample.

\section{Procedure}

List of Patients who had scheduled for ABG analysis in emergency and critical care units were contacted by the researcher to clarify the aim, nature of the study and to obtain the informed consent. The application of ice packs was provided for the study group subjects. An ice pack was put over the proposed site before puncture and was secured with a loose dressing for 10 minutes. Later, ice pack was removed immediately before arterial puncture with no time gap. A 10-minute application of ice was recommended in the previous studies that done by Sauls and Bleakley to cool the tissue and cause analgesia at the proposed site of puncture $[15,18]$. On the other hand, the control group participants didn't receive any treatment trials before withdrawing the arterial sample. The researcher withdrew all the arterial samples in both groups utilizing 2-mL syringes with 25-gauge needles.

\section{Statistical analysis}

Data were calculated and analyzed using SPSS version 22. Descriptive analysis was used for all variables such as the mean and standard deviation to describe base line data, pain score and heart rate. As well, inferential statistics was used such as Independent t-tests for the analysis of variation in both groups.

\section{Result}

The mean age for the study and control groups 
was 56 (2.1) and 54 (2.1) years, respectively. No significant statistical differences were found between the study and control group regarding age, gender, and previous arterial puncture (TABLE 1).

As can be seen from TABLE 2 that there was significant statistical differences among the study and control group regarding pain scores $(\mathrm{t}=2.36 ; \mathrm{p}=0.01)$. As the study group who participated in ice application reported lower pain $(7.36 \pm 1.34)$ than the control group who didn't participate $(7.88 \pm 0.79)$. As well, there was significant statistical differences between both groups regarding heart rate during arterial puncture $(\mathrm{t}=1.82 ; \mathrm{p}=0.03)$. As the study group recorded lower mean pulse score $(78 \pm 11.24)$ than the control group $(86 \pm 6.37)$.

As shown in TABLE 3 that the younger age groups (20-29) recorded lower mean pain scores during arterial puncture than the older age groups in the study group when compared to the control group. As well, the mean pain score during arterial puncture was lower among female than male patients in the study group. On the other hand, female patients revealed higher mean pain scores than male patients in the control group.

\section{Discussion}

The aim of the study was to assess the effect of the local application of ice pack on reducing pain perceived by patients during the arterial puncture. The current study revealed that the mean pain score on a visual analog scale score among study group subjects who underwent application of ice pack for 10 minutes was lower $(7.36+1.34)$ than the control group subjects whose visual analog scale score was $7.88+0.79$. This Study is supported partially by other similar study done by Jeffery who investigated whether pre-cooling of radial pulse site for three minutes with ice pack can decrease the pain during arterial puncture and revealed that applying ice pack before arterial puncture for three minutes significantly reduced the pain during withdrawal of arterial blood gases when compared with a control group [19]. On the contrary, our earlier

\begin{tabular}{|c|c|c|}
\hline Table 1. Baseline characteristics of patients in both groups & \\
\hline Variables & Study group & Control group \\
\hline Patients' number & 50 & 50 \\
\hline Age (mean, SD) & $56 \pm 2.1$ & $54 \pm 2.1$ \\
\hline Male (N\%) & $31(62 \%)$ & $27(54 \%)$ \\
\hline Female (N\%) & $19(38 \%)$ & $23(46 \%)$ \\
\hline Previous arterial puncture (N\%)f & $10(20 \%)$ & $11(22 \%)$ \\
\hline
\end{tabular}

\begin{tabular}{|c|c|c|c|c|}
\hline Table 2. Comparison of mean pain and heart rate scores in both groups & & \\
\hline Variables & Study group & Control group & t value & P value \\
\hline $\begin{array}{c}\text { Immediate Pain scores after puncture } \\
\text { (mean } \pm \text { SD) }\end{array}$ & $7.36 \pm 1.34$ & $7.88 \pm 0.79$ & 2.36 & 0.01 \\
\hline $\begin{array}{c}\text { heart rate scores before puncture } \\
\text { (mean } \pm \text { SD) }\end{array}$ & $74.1 \pm 11.33$ & $74 \pm 10.6$ & 0.08 & $0.46(\mathrm{n} . \mathrm{s})$ \\
\hline $\begin{array}{c}\text { heart rate scores during puncture } \\
\text { (mean } \pm \text { SD) }\end{array}$ & $78 \pm 11.24$ & $86 \pm 6.37$ & $\mathrm{t}=1.82$ & $\mathrm{p}=0.03$ \\
\hline $\mathrm{t}$ and $\mathrm{p}$ & $\mathrm{t}=1.82 ; \mathrm{p}=0.03$ & $\mathrm{t}=6.8 ; \mathrm{p}<0.00001$ & & \\
\hline
\end{tabular}

\begin{tabular}{|c|c|c|c|c|}
\hline Variables & Study group & Control group & t- test & $P$ value \\
\hline \multicolumn{5}{|c|}{ Age(mean SD) } \\
\hline $20-29$ & $6(0)$ & $7.6( \pm 1.15)$ & 2.69 & $0.02 *$ \\
\hline $30-39$ & $7.75( \pm 0.8)$ & $8( \pm 0.6)$ & 0.59 & 0.28 (n.s) \\
\hline $40-49$ & $6.7( \pm 1.4)$ & $7.4( \pm 0.7)$ & 1.05 & 0.15 (n.s) \\
\hline $50-59$ & $7.8( \pm 0.9)$ & $8( \pm 0.7)$ & 0.75 & 0.22 (n.s) \\
\hline $60-69$ & $7.5( \pm 1.5)$ & $7.5( \pm 0.9)$ & 0.0 & $0.5(\mathrm{n} . \mathrm{s})$ \\
\hline $70-79$ & $7.4( \pm 1.9)$ & $8( \pm 0.4)$ & 0.97 & 0.1 (n.s) \\
\hline$\geq 80$ & $6.3( \pm 0.5)$ & $6( \pm 0.0)$ & 0.1 & $0.2(\mathrm{n} . \mathrm{s})$ \\
\hline \multicolumn{5}{|c|}{ Sex(mean SD) } \\
\hline Male & $7.38( \pm 1.4)$ & $7.77( \pm 0.8)$ & 1.27 & $0.10(n . s)$ \\
\hline Female & $7.31( \pm 1.24)$ & $8( \pm 0.7)$ & 2.15 & $0.01 *$ \\
\hline
\end{tabular}


study trials found those three minutes was inadequate in duration to produce conduction block in all patients. Accordingly, application of ice pack for 10 minutes was chosen and evidenced by previous study done by researchers $[15,18]$.This finding could be interpreted in light of Trescot who stated that the application of cold to tissues creates a conduction block [12], similar to the effect of local anesthetics. This finding is also agreed with Watkins, et al who investigated the effect of ice packs on postoperative middle incision pain and found that pain was decreased significantly in narcotic and cryotherapy use among patients [12].

Similarly, researchers also found that pretreatment of ice application were effective in relieving pain related to intra-dermal injection [11]. On the other hand, our study findings are contradicted with previous study done by Sauls who investigated the effect of ice application on reducing pain perceived by patients during removal of the chest tube. They detected no significant clinical differences between the study and control groups [18].

Our findings found that pain score was lower in younger patients than older patients in the study group when compared to control group. So there were significant statistical differences regarding perception of pain by their age. These findings are consistent with other studies done by $[2,17]$. On the contrary, these findings are inconsistent with Bastami Azadi \& Mayel who examined the effect of the application of ice pack on pain level during arterial punctures and revealed that the mean pain score was lower in older patients than younger patients [21]. Furthermore, our findings revealed that heart rates were differed significantly between the two groups, as the study group recorded lower heart rate when compared to the control group. This difference in heart rates between two groups contradicted with other similar study done by researchers who found the heart rates weren't differed significantly during the procedure between the two groups [21]. Moreover, all patients in the study group who previous trial of arterial punctures had reported that the use of cold packs didn't decrease the pain adequately during the withdrawal of arterial sample. This finding is agreed with Tran findings who found that patients who had previous trial of arterial puncture perceived more pain than the patients in the control group [17]. Contrary to our study findings, other similar study done by Bastami Azadi \& Mayel revealed that all patients in the study group who previous attempt of arterial punctures had reported that applying ice packs before arterial puncture decreased pain effectively [21].

Despite the fact that the study findings illustrated that cold ice pack was an effective method to relieve pain during arterial puncture, further researches are required in these areas to provides a data base for health care providers. It is crucial that the critical care nurse utilize evidence-based non pharmacological pain management guidelines for pain control to provide comprehensive care for their patients.

\section{Conclusion}

Results of this research provide evidence to support the application of ice pack before arterial puncture .It might be a simple, safe, and effective method of reducing hazards and physiologic responses that may arise from pain during arterial puncture. However, further researches are needed to study the impact of patients' demographic characteristics and different duration of ice application on perception of pain during arterial puncture.

\section{Acknowledgement}

The authors would like to thank all administrators, patients and staff nurses who help the researcher to conduct this study. 


\section{REFERENCES}

Hudson TL, Dukes SF, Reilly K. Use of local anaesthesia for arterial punctures. Am. J. Crit. Care. 15(6), 595-99 (2006).

Matheson L, Stephenson M, Huber B. Reducing Pain Associated with Arterial Punctures for Blood Gas Analysis. Pain Manag. Nurs. 15(3), 619-624 (2014).

Aaron SD, Vandemheen KL, Naftel SA, Lewis MJ, Rodger MA. Topical tetracaine prior to arterial puncture: a randomized, placebo-controlled clinical trial. Respir. Med. 979(11), 1195-1199 (2003).

Malley W. Arterial blood gases: Unnecessary cost, discomfort and delay of care-or vital lifesaving information. Am Association Respir. Care 34(1), 2527 (2010).

Pourghaznein T, Azimi AV, Jafarabadi MA. The effect of injection duration and injection site on pain and bruising of subcutaneous injection of heparin. J. Clin. Nurs. 23(7-8), 1105-1113 (2014).

Sawyer J, Febbraro S, Masud S, Ashburn MA, Campbell JC. Heated lidocaine/ tetracaine patch (SyneraTM, RapydanTM) compared with lidocaine/prilocaine cream (EMLAw) for topical anaesthesia before vascular access. Br J Anaesth. 102(2), 210-215 (2009).

Ricci SS, Kyle T. Maternity and pediatric nursing. Wolters Kluwer, Lippincott
Williams \& Wilkins, Philadelphia, New York, pp 854-861, 878888,1062-1607,1405-1410 (2009).

Timby BK. Fundamental nursing skills and concepts. $9^{\text {th }}$ edn., Wolter Kluwer, Lippincott Williams \& Wilkins: Philadelphia, pp 435-447 (2009).

Kuivalainen AM, Ebeling F, Rosenberg P. Warmed and buffered lidocaine for pain relief during bone marrow aspiration and biopsy. A randomized and controlled trial. Scand. J. Pain 5(1), 43-47 (2014).

France JE, Beech FJ, Jakeman N, Benger JR (2008). Anaesthesia for arterial puncture in the emergency department: A randomized trial of subcutaneous lidocaine, ethyl chloride or nothing. Eur. J. Emerg. Med. 15(4),218-220 (2008).

Yoon WY, Chung SP, Lee HS, Park YS. Analgesic pretreatment for antibiotic skin test: vapocoolant spray vs ice cube. Am. J. Emerg. Med. 26(1),59-61 (2008).

Trescot AM. Cryoanalgesia in interventional pain management. Pain Physician. 6(3),345-360 (2003).

Taghizadeh F, Ellison T, Traylor-Knowles M. Evaluation of pain associated with facial injections using Cool Skin in rhytidectomy. J. Pain Res. 309-313 (2011).

Saeliw P, Preechawai P, Aui-aree $\mathrm{N}$. Evaluating the effects of ice application on patient comfort before and after botulinum type $\mathrm{A}$ injections.
J. Med. Assoc. Thai. 93(10),1200-1204 (2010).

Bleakley C, McDonough S. The use of ice in the treatment of acute softtissue injury: a systematic review of randomized controlled trials. Am. J. Sports Med. 32(1),251-261 (2004).

Algafly, AA, George PK. The effect of cryotherapy on nerve conduction velocity, pain threshold and pain tolerance. Br. J. Sports Med. Jun 41(6), 365-336 (2007).

Tran NQ, Pretto JJ, Worsnop CJ. A randomized controlled trial of the effectiveness of topical amethocaine in reducing pain during arterial puncture. Chest. 122(4):1357-1360 (2002).

Sauls J. The use of ice for pain associated with chest tube removal. Pain Manag. Nurs. 3(2),44-52 (2002).

Jeffrey M, Haynes RR. Randomized Controlled Trial of Cryoanalgesia (Ice Bag) to Reduce Pain Associated With Arterial Puncture. Respir. Care. 60(1), (2015).

Watkins AA, Johnson TV, Shrewsberry AB, et al. Ice Packs Reduce Postoperative Midline Incision Pain and Narcotic Use: A Randomized Controlled Trial. J. Am. Coll. Surg. 219(3), 511-517 (2014).

Bastami, M, Azadi A, Mayel M. The Use of Ice Pack for Pain Associated with Arterial Punctures. J. Clin. Diagn. Res. 9(8),JC07-JC09 (2015). 